\title{
Buried Deep Inside: 'The Cement Garden’ as a Trauma Narrative
}

\author{
Sharfudden M \\ Research Scholar, Department of English \\ Zamorin's Guruvayurappan College \\ Calicut, Kerala, India \\ sharfudden@gmail.com
}

Dr Rajani B

Supervising Teacher

Research Scholar, Department of English

Zamorin's Guruvayurappan College

Calicut, Kerala, India

\begin{abstract}
'The Cement Garden' is a British novel written by Ian McEwan. The short story revolves around four siblings left alone to deal with the trauma caused by the death of their parents. The story is narrated by Jack who is portrayed as a shabby and unhygienic pervert. He begins the story with a mere mention of his father with whom he doesn't share a happy relationship. His father passes away while attempting to create a cement garden around their house. Being burdened with managing the responsibilities all alone their mother feels tired on most days and falls sick. As a result, she keeps to her room on most days while the siblings manage the household. The family has no connection with society. Neither relatives nor neighbors ever visit them. The children don't have close friends at school. They never invite any of their
\end{abstract}


friends' home. Only the youngest of the sibling Tom is shown to have a friend with whom he plays in the neighborhood. In this study, I focus on the significance of the role played by society and culture in easing the impact of trauma on children. My understanding of the narrative is that the absence of strong cultural identity and family connections make the children perceive trauma as a regular life event and they think it can be easily handled by them. Such misconception results in the older siblings taking up the role of absent parents and entering a relationship of incest. They suppress trauma through the false belief that such a relationship will prevent the family from breaking apart.

Keywords: Childhood, Parental Death, Trauma, Sibling Relations, Incest

Death of a parent is among the most difficult events in the life of a child. Childhood parental death can expose the children to unpredictable challenges including change in social existence, economic instability, etc. Healthy adaptation to change becomes a crucial challenge for the children as they feel helpless and trapped in the situation. Along with the loss of caring parent and absence of support from elders or surviving parent can thrust trauma in the children. The chances of trauma stand increased when the child feels disempowered and disconnected with others, lacking social support. In such cases sharing of distressing event socially is a less likely phenomenon. Instead, the victim will suffer in silence and display the impact of trauma through their behavioral pattern forming Post-Traumatic Stress Disorder (PTSD) as stated by Judith Lewis Herman in 'Trauma and Recovery' (1992). Moreover, the victim feels trauma acutely challenging to be explained verbally. The writings of Cathy Caruth in 'Trauma: Exploration in Memory' (1995), and 'Unclaimed Experience' (1996) suggest that the victim often share their vulnerability through sudden changes in behavior, eating habits, sleeplessness, hyperactivity, avoidance, and abnormal sexual behavior, etc. Such changed behavioural patterns are adopted to cope with the tremors of 
trauma. Lately, creativity has been particularly effective in exploring ramifications of trauma including guilt, incest, madness, suicide, etc. Literature has acted like an overly significant medium to undrape the pains and horrors of trauma victims and exhibit them through divergent forms of writings.

The Cement Garden is an exceptional short read written by Ian McEwan. Though the time and place of story setting are unknown it can be inferred that the era is post Second World War and the backdrop is a western urban neighborhood. The novel explores trauma and post-traumatic stress disorder among four siblings who have first encountered the death of their father soon followed by the death of their mother. The narrative speaks of the different means adopted by four siblings to suppress their trauma. A reader feels intrigued by how different characters of the novel react differently to the same traumatic event.

Cathy Caruth argues with Judith Herman that "trauma explores various modes of domination and is thus met with various modes of silencing and denial" in "Listening to trauma: Conversations with leaders in the theory and treatment of catastrophic experience' (2014). The Cement Garden discusses silence and denial portrayed through childhood psychological issues of the four affected children Julie, Jack, Sue, and Tom. The story explores depths of dark concepts like savagery, psychic anxieties, sibling relationships, and incest.

The narrative begins with a scene where Jack is helping his father to put a new layer of cement in their backyard. The story is narrated from Jack's perspective. He describes himself as a lazy, undisciplined, unhygienic pervert. Jack doesn't share a healthy relationship with his family except for his mother. He considers his father insignificant in the narrative as he states that the father's part of the story has been included to justify the large quantity of cement available in their cellar. Despite Jack's father is a heart attack survivor, Jack doesn't care about his father's poor health condition when the later carries and mixes a large quantity 
of cement. Jack takes the least effort in helping his father. Instead, he excuses himself to the bathroom where he masturbates imagining his sisters. By the time Jack is back, he sees his father lying on the floor. Despite being aware that his father may need medical help, he walks slowly towards his father and shows no urgency to aid him medically. It is observed that Jack doesn't mourn his father's death. Instead, he feels relieved. After his father's death, Jack's mother manages the whole household by herself. As a result, she falls sick and keeps confined to her room while the children take up household chores to manage the family. After a short struggle with her illness, their mother passes away. Though the children mourn her loss but only for a short time. They attempt to hide the fact of their mother's death. The children fear that if the outer world becomes aware of their parents' death they will be sent to foster homes. So, they decide to use the remaining cement to bury their mother in a box by the cellar. Soon both Jack and Julie take up the role of father and mother in the family. Being young and inexperienced they are unable to keep the household in order. The story describes the house in a mess with unkempt rooms and foul smell coming from the kitchen. During this period both Julie and Jack establish a relation of incest with each other. Julie also has a boyfriend Derek who keeps visiting their house. Jack feels insecure with Derek as he thinks that Julie loves Derek more than him. The insecurity furthers when the other siblings Sue and Tom also like Derek. As the story unfolds Julie is seen to show an emotional and physical inclination towards Jack. Derek discovers the secret in the cellar and learns about the incestuous relationship between Julie and Jack. However, the narrative comes to a sudden halt as the vehicles with siren and quick steps dominate the house.

Though the death of both the parents is not an express shock to the children they are more concerned about their economic instability and social existence. These factors drive the children to bury their mother in the cellar without letting the society know about it. Such a phenomenon is rare among the human community as we are social beings with socially 
acceptable norms and practices of sharing important life events with society. A secret burial of the mother shows the extent of the family's disconnect from society. It also leaves questions on the culture of the society being portrayed by Jack. The cultural and social factors depicted in this narrative have influenced the family in such a manner that the children lack the concept of living together in a society. They develop a deep disconnect from society. In his narration, Jack states that the family never had any visitors in the form of either friends or relatives. Even the children didn't bring their friends home. After their patent's death, the children disconnect themselves from the outer world. They feel trapped in the situation and show the symptoms of post-traumatic stress disorder through different behavioral patterns.

Lack of parental attention, proper guidance, and disconnect in the family lead Jack to develop sexual feelings towards his sisters. He longs to examine the private parts of his sisters' body and masturbates imagining his sisters. He tells the readers that, "upstairs, aware of his impatience, I worked on myself rapidly. As usual, the image before me was Julie's hand between Sue's legs (McEwan, 14).” Though Jack loved his mother and cried over her death the emotional disconnect is evident as the children could not stop giggling while covering up her body. However, the trauma of her death surfaced in him as blankness and he would imagine any woman in the street as his mother being alive. Initially, he avoided going out or spending time with his siblings. He explains his post-traumatic stress disorder as "I went straight upstairs to my bedroom, and although I did not meet or hear anyone, I knew the others were in (McEwan, 60)." Mostly Jack would sleep, simply lie down in his bed or masturbate as explained by him "I woke in the late morning, masturbated and dozed off again (McEwan, 68)." His sleeping patterns also changed as now he would wake up at oddly late hours of the day. Jack explains that he felt there was no use of waking up. He would also visit the cellar and imagined his mother being alive and talking to him. Jack had nightmares of his mother sitting by the armchair of his room staring at him and advising him to stop while he 
continued to masturbate in front of her. Jack kept so much to himself that he felt uncomfortable when Julie's boyfriend Darek came home. He explains time spent out with Darek as "I had a strange sensation of having been away several months and that many things had happened in my absence (McEwan, 87)." Jack also feels insecure about Darek and mends his unhygienic lifestyle to gain Julie's attention. The bonding between Julie and Jack strengthens to reveal the relationship of incest. When Darek finds out about this awkward relationship and he questions Julie to which she confesses as "How long has this been going on? I was glad I could not see him. Ages, Julie said, ages and ages (McEwan, 112).”

The trauma of her mother left Julie also vulnerable to a natural emotional reaction. Though Julie cried at her mother's untimely death she was quick to garner efforts to keep the family together. It is strange to notice that the siblings are giggling while covering their dead mother and carrying her to the cellar. Being the eldest sibling Julie took over the role of new house head after her mother's death. She laid out the plans to keep her mother's death a secret with an intention that the siblings stayed together in their own house. With Tom's increasing tantrums Julie becomes a mother figure to him and meets his impatient behavior with utmost patience and care. It is doubtful why she and Sue dress Tom like a girl both before and after their mother's death. Being the elder one in the family Julie manages the finances. Julie gives two pounds to each of her siblings while she spends more money on herself. Her spending habits and lifestyle undergo sudden changes after the death of their mother. She buys fashionable clothes as stated by Jack "She wore clothes I had never seen before, a silk blouse and a brown velvet skirt (McEwan, 68)." Julie went out with anyone who would buy her things. She would go out on most of the afternoons. When Jack questioned Julie, she would respond to him rudely such that he stopped asking her about it altogether. Julie paid much attention to her appearance. She spent much time getting ready, taking long baths, brushing her hair, and doing eye makeup. Though Derek is her boyfriend she fails to establish physical 
intimacy with him. Instead, she seduces Jack into a relationship of incest with her. Both Jack and Julie deceive their psyche and find solace to their parental loss through a relation of unapologetic incest.

Sue was the only child who suggested giving their mother a proper funeral, but Jack tells her that if the society knows about their mother's death, they will be separated from each other. Sue felt miserable and lost at the realization of the mother's death. Later, Sue would reflect her post-traumatic stress disorder by spending most of her time in her room reading books and writing. The floor of her room is described to be full of books. With her mother's death, she felt that there was nothing to do other than read books as stated by Sue "I like reading, Sue said, and there's nothing else to do (McEwan, 78)" and "I don't feel like doing anything else (McEwan, 78)." She also spent time writing in her notebook but never shared it with any of her siblings except once to Jack. In the later readings, it can be noticed that she is aware of Jack and Julie's relation of incest as she is not shocked when Derek screams and shouts about the relationship.

Tom being the youngest in the family feels devastated with the death of his mother. It is difficult to say if Tom understands the concept of death, but he feels heavily disturbed and keeps crying at the odd hours of the day. Being small and innocent Tom cannot maintain secrets and he confides of his mother's death to his friend and tells the secret of the cellar to Derek as well. Sensing his mother's absence Tom views Julie as a mother figure and would cry loudly to gain her attention as "He lay on the floor, clutching his head and screamed so loud that Sue came running out of her bedroom (McEwan, 67)." Tom would often sit in Julie's lap sucking his thumb where he would sleep off as well. The character of Tom looks to have drawn a blind eye towards the reality of his mother's death and uses his sexuality to cope up with the trauma caused due to his mother's death. He would often dress in girl's 
clothes and would also go to the tower block to play with his friend in Sue's skirt as "Quite often now Tom played in the street in Sue's skirt (McEwan, 69).”

The author has effectively portrayed complex psychological disturbances through the medium of four children belonging to different age groups. Though the geographical setting of the story is not established it can be understood that the setup of the narrative is a western society with no deep cultural connect. The reader has limited access to understanding Jack's parents and his siblings as the story is narrated from a single person's point of view. His narrative also lacks the display of emotions and is subjective in the description of his sibling's post-traumatic stress disorder. Also, the narrative ends abruptly and doesn't speak of recovery from trauma. Since the story of unrecovered trauma is told only from Jack's point of view McEwan's narrative cannot be considered to be a reliable narrative of trauma. Jack's sexual desires with his sisters, his shady mindscape, unhealthy and unhygienic habits existed even before the death of their parents. However, it is not easy for a child to carry on with regular life in an unaffected manner after the death of their parents especially when they lack support from community and relatives. Jack justifies his internal conflicts through his and the sibling's post-traumatic stress disorder. Jack's narrative is an outburst of his suppressed feelings which leads him to create an alternate and unnatural reality with his sister. Incest makes him feel secure and belong to the family. Though the narrative takes place in an urban setting it speaks of family's disconnect from the society. The emotionally wounded situation depicted in the story of the children is a reflection of the reclusive state of society. 


\section{Works Cited}

Caruth, Cathy. "Listening to trauma: Conversations with leaders in the theory and treatment of catastrophic experience." The International Journal of Psychoanalysis (2014): 392. 28 August 2019. <https://onlinelibrary.wiley.com/doi/epdf/10.1111/1745$8315.12482>$.

—. The Unclaimed Experience : Trauma, Narrative and History. Baltimore : John Hopkins University Press, 1996.

—. Trauma: Exploration in memory. Baltimore : John Hopkins University Press, 1995.

Herman, Judith Lewis. Trauma and Recovery. Basic Books, 1992.

McEwan, Ian. The Cement Garden. RosettaBooks, LLC, 2009. Electronic. 